\title{
The Role of Dorsal Hippocampal Dopamine DI-Type Receptors in Social Learning, Social Interactions, and Food Intake in Male and Female Mice
}

\author{
Richard Matta', Angela N Tiessen' and Elena Choleris*,' \\ 'Department of Psychology and Neuroscience Program, University of Guelph, Guelph, ON, Canada
}

\begin{abstract}
The neurobiological mechanisms underlying social learning (ie, in which an animal's learning is influenced by another) are slowly being unraveled. Previous work with systemic treatments shows that dopamine (DA) DI-type receptors mediate social learning in the social transmission of food preferences (STFP) in mice. This study examines the involvement of one brain region underlying this effect. The ventral tegmental area has dopaminergic projections to many limbic structures, including the hippocampus - a site important for social learning in the STFP in rodents. In this study, adult male and female CD-I mice received a dorsal hippocampal microinfusion of the DI-like receptor antagonist $\mathrm{SCH} 23390$ at I, 2, 4, or $6 \mu \mathrm{g} / \mathrm{\mu l} 15 \mathrm{~min}$ before a $30 \mathrm{~min}$ social interaction with a same-sex conspecific, in which mice had the opportunity to learn a socially transmitted food preference. Results show that social learning was blocked in female mice microinfused with $6 \mu \mathrm{g} / \mu \mathrm{ll}$, and in males infused with I, 4, or $6 \mu \mathrm{g} / \mu \mathrm{l}$ of SCH23390. This social learning impairment could not be explained by changes in total food intake, or olfactory discrimination. A detailed analysis of the social interactions also revealed that although SCH23390 did not affect oronasal investigation for either sex, drug treatments affected other social behaviors in a sex-specific manner; there was primarily a reduction in agonistic-related behaviors among males, and social investigatory-related behaviors among females. Thus, this study shows that dorsal hippocampal DI-type receptors mediate social learning and social behaviors in male and female mice. Neuropsychopharmacology (2017) 42, 2344-2353; doi:I0.1038/npp.2017.43; published online 29 March 2017
\end{abstract}

\section{INTRODUCTION}

Social learning refers to learning that is influenced by observation of, or interaction with, another animal (typically a conspecific) or its products (such as odor cues; Box, 1984; Galef, 1988; Heyes, 1994). Social learning has been reported in various species/taxa, and is an adaptive and important biological phenomenon (Hoppitt and Laland, 2013), as it enables an animal to use the 'expertise of others' (Russon, 1997) to potentially circumvent some of the costs that may be associated with trial-and-error individual learning. One way to examine social learning in the laboratory is with the social transmission of food preferences (STFP; Galef et al, 1984) in which an observer (OBS) animal interacts with a same-sex demonstrator (DEM) conspecific that has just consumed a novel food. If social learning occurs during the social interaction, the OBS will show a preference for the DEM food type in a subsequent test. The STFP depends on the OBS detecting the scent of the food mixed with carbon disulfide $\left(\mathrm{CS}_{2}\right)$, a semiochemical found in exhaled air on the breath of the DEM (Galef et al, 1988), that is detected by

* Correspondence: Dr E Choleris, Department of Psychology and Neuroscience Program, University of Guelph, 50 Stone Road East, Guelph, ON NIG 2WI, Canada, Tel: + I 519824 4I20, Ext: 52729, Fax: + I 519837 8629, E-mail: echoleri@uoguelph.ca

Received 23 September 2016 ; revised 28 December 20 I 6; accepted 13 February 2017; accepted article preview 27 February 2017
$\mathrm{CS}_{2}$-selective olfactory neurons in the rodent olfactory epithelium (Arakawa et al, 2013; Munger et al, 2010). Oronasal investigation (sniffing the mouth/face area) is therefore necessary for social learning in the STFP in both mice (Valsecchi and Galef, 1989) and rats (Galef and Stein, 1985).

Brain regions that are involved in the STFP include the basal forebrain and frontal, piriform and orbitofrontal cortices; gonadal hormones such as estrogens/progesterone, and several neurochemical systems, including the oxytocin/ vasopressin, cholinergic, opioid, and glutamatergic system have also been shown to regulate the STFP (reviewed in Choleris et al, 2009; Ervin et al, 2015; Matta et al, 2016). In addition, the neurotransmitter dopamine (DA) has been found to mediate social learning in the STFP (Choleris et al, 2011). When female mice were systemically administered a D1-type (D1/D5) receptor antagonist (SCH23390) before the social interaction in the STFP, social learning was impaired, without total food intake being affected (Choleris et al, 2011). Conversely, a D2-type (D2/D3/D4) receptor antagonist (Raclopride) had no effect on social learning; however, it reduced the total amount of food consumed (Choleris et al, 2011). Furthermore, DA transporter knockout (DAT KO) OBS mice are impaired in their ability to socially learn a food preference (Wong et al, 2012), or they even prefer to eat the food not consumed by their DEM (Rodriguiz et al, 2004). Collectively, these studies suggest a role for the DAT and D1-type receptors in social learning in the STFP. However, 
the specific brain region(s) of D1-type receptor action remain unknown.

Dopaminergic neurons in the ventral tegmental area (VTA) project to many limbic structures, including the hippocampus (McNamara et al, 2014; Wise, 2004) - a brain region that has been implicated in the STFP (Bunsey and Eichenbaum, 1995; Clark et al, 2002; Countryman and Gold, 2007). Pharmacological investigations show that dorsal hippocampal D1-type receptors are involved in various nonsocial types of learning (reviewed in Hansen and Manahan-Vaughan, 2014). D1-type receptors in the dorsal hippocampus also contribute to the encoding of novel/motivationally relevant information that is processed by the VTA-hippocampal dopaminergic loop (Lisman and Grace, 2005; Otmakhova and Lisman, 1996; Rossato et al, 2009). It can thus be hypothesized that D1-type receptors in the dorsal hippocampus may mediate social learning in the STFP.

The objective of this study was to assess whether dorsal hippocampal administration of SCH23390 before the social interactions would block social learning in male and female mice. Possible secondary effects of drug treatment on food intake and olfactory discrimination were also assessed. In addition, a detailed behavioral analysis was conducted on the social interactions during the STFP (Clipperton et al, 2008) to determine whether SCH23390 effects on social learning were associated with effects on various social and nonsocial behaviors. Finally, given the strong role of estrogens in mediating social learning in the STFP in mice (Ervin et al, 2015), and the established effects of estrogens/progesterone in regulating the mesolimbic DA system (Thompson and Moss, 1997), we also monitored the female estrous cycle, and assessed sex differences.

\section{MATERIALS AND METHODS}

\section{Animals}

Male and female CD-1 mice (Mus musculus) were obtained from Charles River (St Constant, QC, Canada) at 2 to 3 months of age. All cages (polyethylene; $26 \times 16 \times 12 \mathrm{~cm}^{3}$ ) contained corncob bedding, plastic shelters, and paper material (environmental enrichment), ad libitum rodent chow (Teklad Global 14\% Protein Rodent Maintenance Diet, Harlan Teklad, Madison, WI), and tap water. Mice were kept on a reversed 12:12 h light/dark cycle (lights off at $0800 \mathrm{~h}$ ). For the STFP, DEMs were reused ( 9-14 times), whereas all OBSs and mice used in the olfactory discrimination task (ODT) were experimentally naive. See Supplementary Information for details on housing conditions. The University of Guelph Institutional Animal Care and Use Committee permitted all experimental procedures that were in line with the guidelines of the Canadian Council on Animal Care.

\section{Surgeries}

To ensure the hormonal status of DEMs did not influence the social learning of OBSs, all DEMs were gonadectomized. All OBSs and mice used in the ODT had bilateral cannulae inserted into their dorsal hippocampi, but were left gonadally intact to examine hormonal effects on social learning
(Choleris et al, 2011; Clipperton et al, 2008; SanchezAndrade et al, 2005) and/or olfactory discrimination. See Supplementary Information for details of surgical procedures.

\section{Diets}

Ground rodent food was flavored with either $1 \%$ ground cinnamon (CIN; McCormick Ground Cinnamon, McCormick Canada, London, Canada) or $2 \%$ powdered cocoa (COC; Fry's Premium Cocoa, Cadbury, Mississauga, Canada). CD-1 mice from Charles River (Quebec) find these two flavored diets equally palatable (Choleris et al, 2011; Clipperton et al, 2008).

\section{Drug}

The D1-like receptor antagonist SCH23390 hydrochloride (Hyttel, 1983; Tocris Biosciences, Ellisville, MO) was dissolved in sterile saline solution $(0.9 \% \mathrm{NaCl})$.

\section{Experimental Procedures}

Full details of all procedures are in Supplementary Information. Briefly, phases of the estrous cycle were determined by taking vaginal smears at the end of the STFP and ODT on the day of testing. Mice were acclimatized to the testing room and food deprived $12-14 \mathrm{~h}$ before testing in the STFP and ODT.

STFP. Same-sex OBS-DEM dyads were pair housed (with perforated steel cage dividers) for at least 3 days before testing. Early in the dark (active) phase of the light cycle under red light, DEMs were moved into a clean cage for $1 \mathrm{~h}$, and were allowed to eat either a CIN or COC diet. DEMs had to consume at least $0.1 \mathrm{~g}$ of flavored food to be used $(n=7$ mice were removed; see Figures 2 and 3 for final sample sizes). After feeding, DEMs were put back into their home cages with their respective OBSs, where dyads were allowed to socially interact freely for $30 \mathrm{~min}$. All social interactions (where social learning occurs) were video recorded from above through clear Plexiglas lids. Following the social interactions, OBSs were placed into the choice test chambers for $8 \mathrm{~h}$ with continuous access to both CIN and COC, and water ad libitum. Feeders were weighed at 1, 2, 4, 6, and $8 \mathrm{~h}$ on a scale precise to $0.01 \mathrm{~g}$ (Sartorius, UK).

At $15 \mathrm{~min}$ before the start of the social interactions, each OBS received an intrahippocampal microinfusion of either SCH23390 (at one of four doses: 1, 2, 4, or $6 \mu \mathrm{g} / \mu \mathrm{l}$ ) or saline solution $(0.9 \% \mathrm{NaCl})$. See Supplementary Information for choice of SCH23390 doses and time delay. The microinjection volume was $0.5 \mu \mathrm{l}$ (per hemisphere) and the flow rate was $0.2 \mu \mathrm{l} / \mathrm{min}$ (PHD 2000 injector; Harvard Apparatus, QC, Canada).

Social interaction videos were scored (The Observer Video software; Noldus Information Technology, Wageningen, The Netherlands) by a trained researcher blind to the OBS treatment group. Only the OBS behaviors were scored for various social and nonsocial behaviors (Supplementary Tables S1 and S2), including general activity, sociability, aggression, exploration, solitary behaviors, and oronasal investigationthat is crucial for the STFP (Clipperton et al, 2008). 
ODT. We tested whether the social learning impairment found in the STFP was due to changes in olfactory discrimination between COC and CIN (the two diets used in the STFP choice test). In their home cage, for four habituation phases, mice were presented with two meshed mason jars, each containing $15 \mathrm{~g}$ of the same diet (ie, either CIN or COC). During the test phase, one jar contained the previously encountered (familiar) diet, and the other a novel diet. Each phase was $5 \mathrm{~min}$ long, with $\sim 1 \mathrm{~min}$ in between.

The time that mice spent investigating (sniffing, within 1-2 $\mathrm{mm}$ ) the meshed area of each food-containing jar was recorded by a trained investigator quietly standing $1 \mathrm{~m}$ away with two stopwatches.

As in the STFP procedures, $15 \mathrm{~min}$ before the first habituation phase, mice received an intrahippocampal microinfusion of either saline solution or SCH23390 at $6 \mu \mathrm{g} / \mu \mathrm{l}$, the highest dose that blocked the STFP in both sexes.

Histology. Mice received an intrahippocampal microinfusion of $1 \%$ Chicago blue dye (in phosphate-buffered saline) at the end of all experimental procedures, and brains were extracted $45 \mathrm{~min}$ after dye infusion. Hippocampal injector placements were assessed from coronal sections (as shown in Supplementary Figures S1 and S2). Similar to previous work (Phan et al, 2015), the dye was largely confined to the dorsal hippocampus (as shown in Supplementary Figure S3). Two mice with off-target cannulae were removed from all analyses. An analysis of the data from animals with offtarget cannulae revealed no significant effect of treatment.

Data handling. For STFP data, a percent of CIN diet consumed by OBSs at $1,2,4,6$, and $8 \mathrm{~h}$ was calculated (CIN/ $(\mathrm{CIN}+\mathrm{COC}) \times 100)$. A statistically significant difference between the CIN preferences of OBSs that had a CIN-fed DEM versus OBSs that had a COC-fed DEM is indicative of a socially learned food preference in a group. In addition, a percent of DEM diet $(\mathrm{DEM} /(\mathrm{DEM}+\mathrm{NONDEM}) \times 100)$ was calculated to compare social learning across different treatment groups. Total food intake was also calculated $(\mathrm{CIN}+\mathrm{COC})$. When an OBS mouse does not consume enough of the two flavored diets $(0.1 \mathrm{~g}$ of food) it speaks to their interest in flavored diets and not to social learning; for this reason, when an OBS mouse did not consume a minimum of $0.1 \mathrm{~g}$ of food at a particular time point, we did not calculate a preference score for them, neither the CIN preference nor the DEM preference score. For ODT data, a percent of novel diet investigation (NDI) was calculated ((time investigating novel diet/total time investigating both diets) $\times 100$ ) for every mouse for all phases. An average NDI value of the four habituation phases was then calculated for each mouse, predicted to be $\sim 50 \%$ (chance) for the identical diets. As mice prefer to investigate novel stimuli more than familiar ones (Choleris et al, 2003), mice that can discriminate between the two diets show significantly higher NDI during test than habituation. Total flavor investigation was also calculated.

All ratio data were arcsin-transformed before being analyzed (as ratios violate the assumption of homogeneity of variance), although all graphs display the original ratio data for ease of interpretation.

\section{Statistical Analyses}

STFP CIN and DEM preference scores were analyzed with mixed model analyses of variance (ANOVAs). CIN and DEM diet preference ratios were only calculated if OBSs had consumed at least $0.1 \mathrm{~g}$ of food at each time point. This resulted in some empty cells at some time points that caused data from a number of animals to be completely eliminated in the repeated measures (RM) ANOVA overall models. Thus, the CIN and DEM preference data were also analyzed at each separate time point. Independent samples $t$-tests compared the CIN preferences of OBSs with COC DEMs with OBSs with CIN DEMs for each sex and treatment group. Similarly, independent samples $t$-tests compared the DEM food preferences of each SCH23390 group and sex with saline-infused control mice. One-sample $t$-tests were also conducted to compare the DEM preference scores to $50 \%$ (chance) for each sex and treatment group.

STFP total intakes, ODT total investigation, and NDI data were analyzed with mixed model ANOVAs. Planned paired samples $t$-tests compared the averaged NDI habituation values to the test NDI values.

Duration, frequency, and latency data of single and grouped behaviors from the social interactions were analyzed with mixed model ANOVAs, or with nonparametric tests (Kruskal-Wallis and Mann-Whitney $U$ ) when normality could not be attained through $\ln$ transformation. Planned independent samples $t$-tests compared saline- with SCH23390-infused mice for each sex.

Separate ANOVAs were also run on female data to include the phase of the estrous cycle as a between-groups variable. In addition, in all models, comparisons between salineinfused males versus females assessed for baseline sex differences.

Binary a priori mean comparisons were planned for all models to increase power and decrease the risk of type II errors. In addition, an overall ANOVA was conducted to reduce the risk of type I errors. According to Rosenthal and Rosnow (1991), this 'protected $t$-tests' approach is the most reasonable or 'ideal' solution when conducting multiple $t$-tests. The post hoc multiple comparisons (Bonferroni and other such highly conservative corrections) were not used in this study because of their likelihood of increasing type II errors above tolerable levels (Nakagawa, 2004). All mean comparisons were planned for the early time points of the choice test, where food preferences are strongest, and usually affected by drug treatment (Choleris et al, 2011; Clipperton et al, 2008).

The Greenhouse-Geisser RM correction was employed. Statistical significance was set to $p<0.05$. Unless otherwise meaningful, only results that are statistically significant are reported. Analyses were performed using SPSS (v.20; IBM, Armonk, NY). See Supplementary Information for more details on statistical analyses.

\section{RESULTS}

\section{Social Learning Study: Effects of Intrahippocampal SCH23390 on Behavior During the Social Interactions}

See Supplementary Information for a detailed report of these results. Importantly, SCH23390 did not affect oronasal 

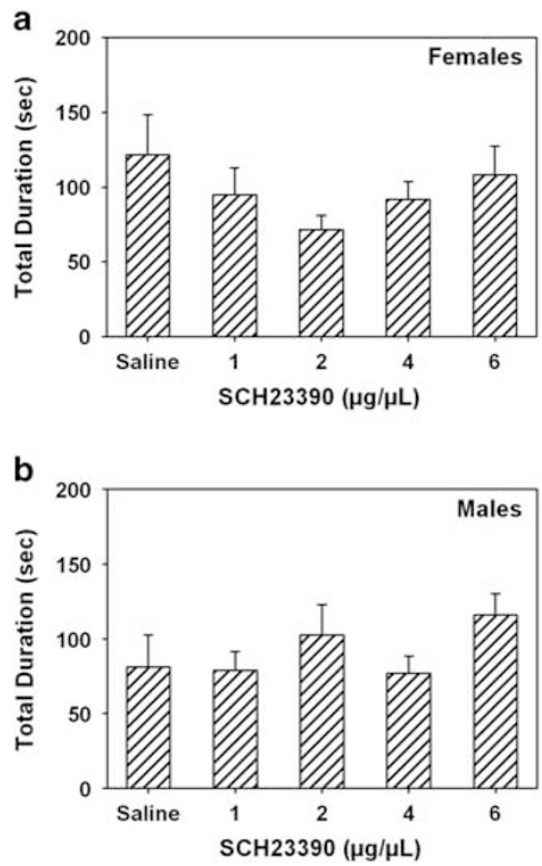

Figure I Oronasal investigation durations (in s) of female (a) and male (b) observer (OBS) mice during the social interactions with their respective same-sex demonstrator (DEM) in the social transmission of food preferences (STFP) study. OBSs were administered a single dorsal hippocampal infusion of either saline vehicle $(n=25$ for females and $n=23$ for males) or the DI-type receptor antagonist $\mathrm{SCH} 23390$ at I $\mu \mathrm{g} / \mathrm{\mu l}$ ( $n=25$ for females and $n=23$ for males), $2 \mu \mathrm{g} / \mu \mathrm{l}$ ( $n=25$ for females and $n=22$ for males), $4 \mu \mathrm{g} / \mu \mathrm{l}$ ( $n=25$ for females and $n=23$ for males), or $6 \mu \mathrm{g} /$ ul ( $n=26$ for females and $n=23$ for males) 15 min before a 30 min social interaction with a same-sex DEM conspecific that recently ate either a $1 \%$ cinnamon $(\mathrm{CIN})$ or a $2 \%$ cocoa (COC) diet. SCH23390 treatment did not significantly affect either female (a) or male (b) oronasal investigation durations. Data are presented as mean+SEM.

investigation durations for either females or males (as shown in Figure 1a and b). Thus, the social learning impairment described below cannot be directly explained by a reduced exposure to the socially carried food odor found on the breath of the DEM (Supplementary Tables S3 and S4). In addition, SCH23390 reduced overall activity for both sexes that was partly attributed to a reduction in nonsocial active behaviors (eg, horizontal/vertical exploration) and a paralleled increase in time spent engaging in nonsocial inactive behaviors (eg, solitary inactivity). Interestingly, SCH23390 affected some social behaviors in a sex-dependent manner: for males, there was mainly a reduction in agonistic behaviors (eg, overt aggression), whereas for females, there was mainly a reduction in social investigatory behaviors (eg, body investigation). Notably, SCH23390 reduced the dominance scores of both sexes (ie, OBSs were more subordinate toward their DEMs).

\section{Social Learning Study: Intrahippocampal SCH23390} Blocks Social Learning and Reduces the Strength of Food Preferences without Affecting Food Intake in Males and Females

The CIN preference scores revealed that female social learning was blocked by $6 \mu \mathrm{g} / \mu \mathrm{l}$ of SCH23390, whereas male social learning was blocked by 1,4 , and $6 \mu \mathrm{g} / \mu \mathrm{l}$ of SCH 23390 (as shown in Figure 2). Consistent with this, the DEM preference scores of both females and males infused with 1, 4 , or $6 \mu \mathrm{g} / \mu \mathrm{l}$ of SCH23390 were significantly lower than the saline-infused control mice of the same sex (as shown in Figure 3). Intrahippocampal SCH23390 did not affect total food intake for either sex (as shown in Figure 4).

The RM ANOVA conducted on the CIN preferences of all OBSs showed a significant time $\times$ treatment $(\mathrm{F}(16,400)=1.84$, $p=0.025)$, time $\times \mathrm{DEM}$ food $(\mathrm{F}(4,400)=3.62, p=0.007)$, and treatment $\times \mathrm{DEM}$ food interaction $(\mathrm{F}(4,100)=3.15$, $p=0.018)$, and main effects of treatment $(\mathrm{F}(4,100)=6.33$, $p<0.001)$ and DEM food $(\mathrm{F}(1,100)=21.05, p<0.001)$.

Independent samples $t$-tests comparing the CIN preferences of OBSs with CIN versus COC-fed DEMs (for each sex and time point) revealed that $\mathrm{SCH} 23390$ impaired social learning in both males and females. Specifically, in the first hour, there was a significant difference between the CIN preferences of OBSs with CIN versus COC-fed DEMs for saline-infused females $(t(15)=4.38, p=0.001)$ and males $(t(18)=6.59, \quad p<0.001), \quad$ females infused with $1 \mu \mathrm{g} / \mu \mathrm{l}$ $(t(18)=2.72, \quad p=0.014), \quad$ and females $\quad(t(14)=3.79$, $p=0.002)$ and males $(t(15)=2.61, p=0.02)$ infused with $2 \mu \mathrm{g} / \mu \mathrm{l}$ of SCH23390. In the second hour, there was a significant difference between the CIN preferences of OBSs with CIN versus COC-fed DEMs for saline-infused females $(t(15)=2.27, p=0.039)$ and males $(t(18)=3.73, p=0.002)$, females infused with $1 \mu \mathrm{g} / \mu \mathrm{l}(t(18)=2.42, p=0.026)$, and females $(t(20)=2.19, p=0.04)$ and males $(t(15)=2.94$, $p=0.010)$ infused with $2 \mu \mathrm{g} / \mu \mathrm{l}$ of SCH23390. In the fourth hour, there was still a significant difference between the CIN preferences of OBSs with CIN versus COC-fed DEMs for saline-infused females $(t(20)=2.32, p=0.031)$ and males $(t(19)=2.47, p=0.023)$, and also females infused with $4 \mu \mathrm{g} / \mu \mathrm{l}$ of SCH23390 showed a significant preference for their DEM food $(t(22)=2.07, p=0.050)$. Finally, in the eighth hour of the choice test, there was a significant difference between the CIN preferences of OBSs with CIN versus COC-fed DEMs for females infused with $4 \mu \mathrm{g} / \mu \mathrm{l}$ of SCH23390 $(t(14)=2.37$, $p=0.033)$. Importantly, there was no significant effect of the DEM food on the CIN preferences of the OBS females infused with $6 \mu \mathrm{g} / \mu \mathrm{l}$, and males infused with 1,4 , and $6 \mu \mathrm{g} / \mu \mathrm{l}$ of SCH23390 at any time points (as shown in Figure 2), indicating that intrahippocampal SCH23390 blocked the STFP at these doses.

The RM ANOVA conducted on the percent of DEM food consumed by OBSs showed a significant main effect of time $(\mathrm{F}(4,440)=4.201, p=0.002)$ and treatment $(\mathrm{F}(4,110)=3.06$, $p=0.02)$. Mixed-model ANOVAs also showed a significant main effect of treatment in the first hour of testing for both females $(\mathrm{F}(4,87)=3.82, p=0.007)$ and males $(\mathrm{F}(4,84)=2.50$, $p=0.048)$. Importantly, planned independent samples $t$-tests further showed that in the first hour of the choice test, both females (saline versus $1 \mu \mathrm{g} / \mu \mathrm{l}: t(35)=2.13, p=0.040$; saline versus $4 \mu \mathrm{g} / \mu \mathrm{l}: t(34)=3.13, p=0.004$; saline versus $6 \mu \mathrm{g} / \mu \mathrm{l}$ : $t(35)=2.99, p=0.005$; as shown in Figure 3$)$ and males (saline versus $1 \mu \mathrm{g} / \mu \mathrm{l}: t(36)=2.59, p=0.014$; saline versus $4 \mu \mathrm{g} / \mu \mathrm{l}: \quad t(31)=3.25, \quad p=0.003 ;$ saline versus $6 \mu \mathrm{g} / \mu \mathrm{l}$ : $t(37)=2.41, p=0.021$; as shown in Figure 3 ) infused with 1,4 , or $6 \mu \mathrm{g} / \mu \mathrm{l}$ of $\mathrm{SCH} 23390$ had a significantly lower preference for their DEM diet than saline-infused OBS control mice (of the same sex). Planned independent samples 

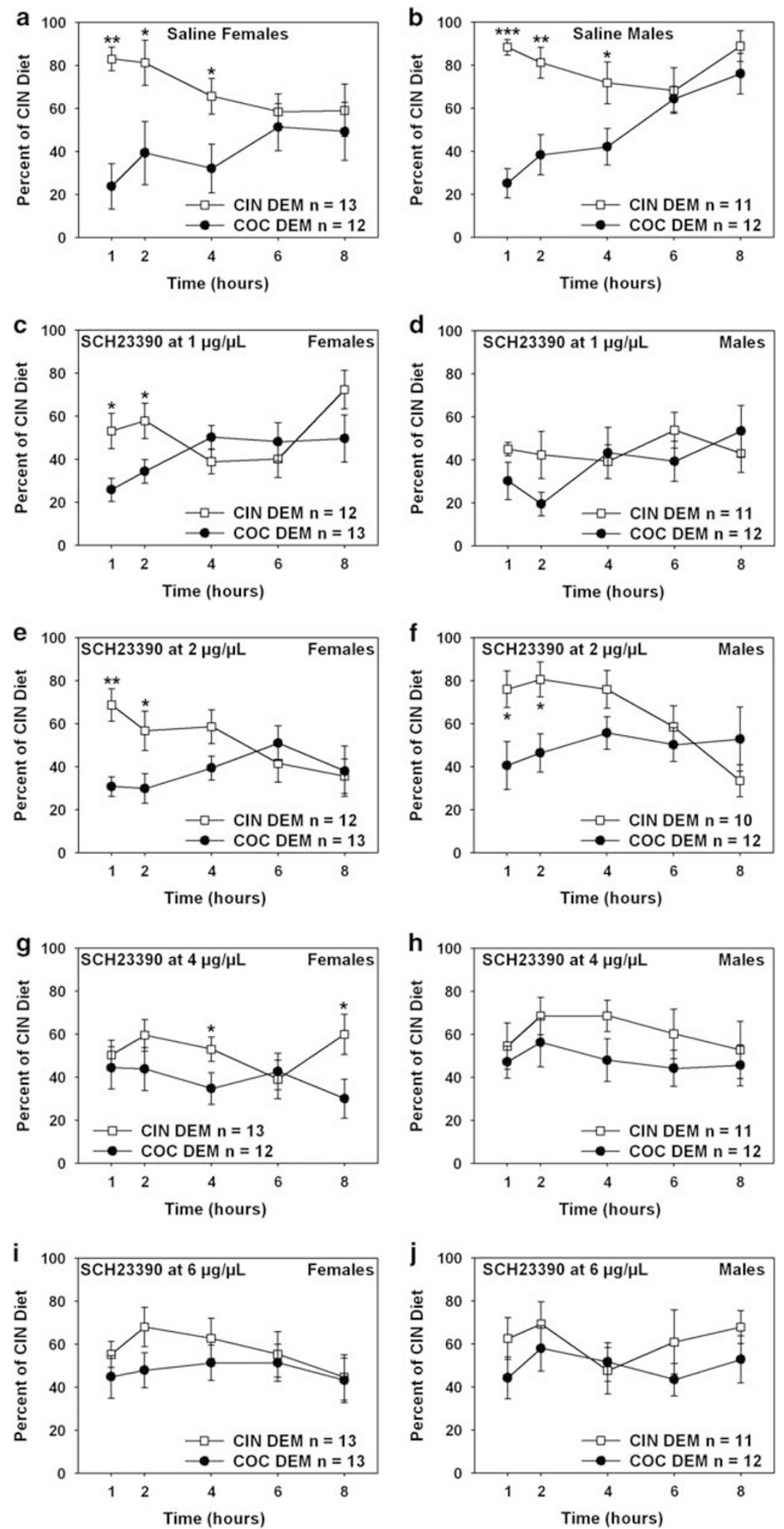

Figure 2 The percent of cinnamon (CIN) diet (CIN diet eaten divided by the total amount of food eaten) for female (a, c, e, $g, i)$ and male (b, $d, f, h, j)$ observer (OBS) mice that were administered a single dorsal hippocampal infusion of either saline vehicle (a, b) or the DI-type receptor antagonist SCH23390 at I $\mu \mathrm{g} / \mathrm{\mu l}(\mathrm{c}, \mathrm{d}), 2 \mu \mathrm{g} / \mathrm{\mu l}(\mathrm{e}, \mathrm{f}), 4 \mu \mathrm{g} / \mathrm{\mu l}(\mathrm{g}, \mathrm{h})$, or $6 \mu \mathrm{g} / \mu \mathrm{l}(\mathrm{i}, \mathrm{j}) 15 \mathrm{~min}$ before a 30 min social interaction (where social learning occurs) with a same-sex demonstrator (DEM) conspecific that recently ate either a $1 \%$ CIN (white squares) or a $2 \%$ cocoa (COC; black circles) diet. CIN preference scores are shown at I, 2, 4, 6, and $8 \mathrm{~h}$ into the OBS choice test. Data are presented as mean \pm SEM. The $n$ reported in the figures reflect the number of OBS mice per group. * $p<0.05$, ** $p<0.01$, **** $p<0.00$ I in comparison between OBS mice that interacted with a CIN-fed DEM versus OBS mice that interacted with a COC-fed DEM. 

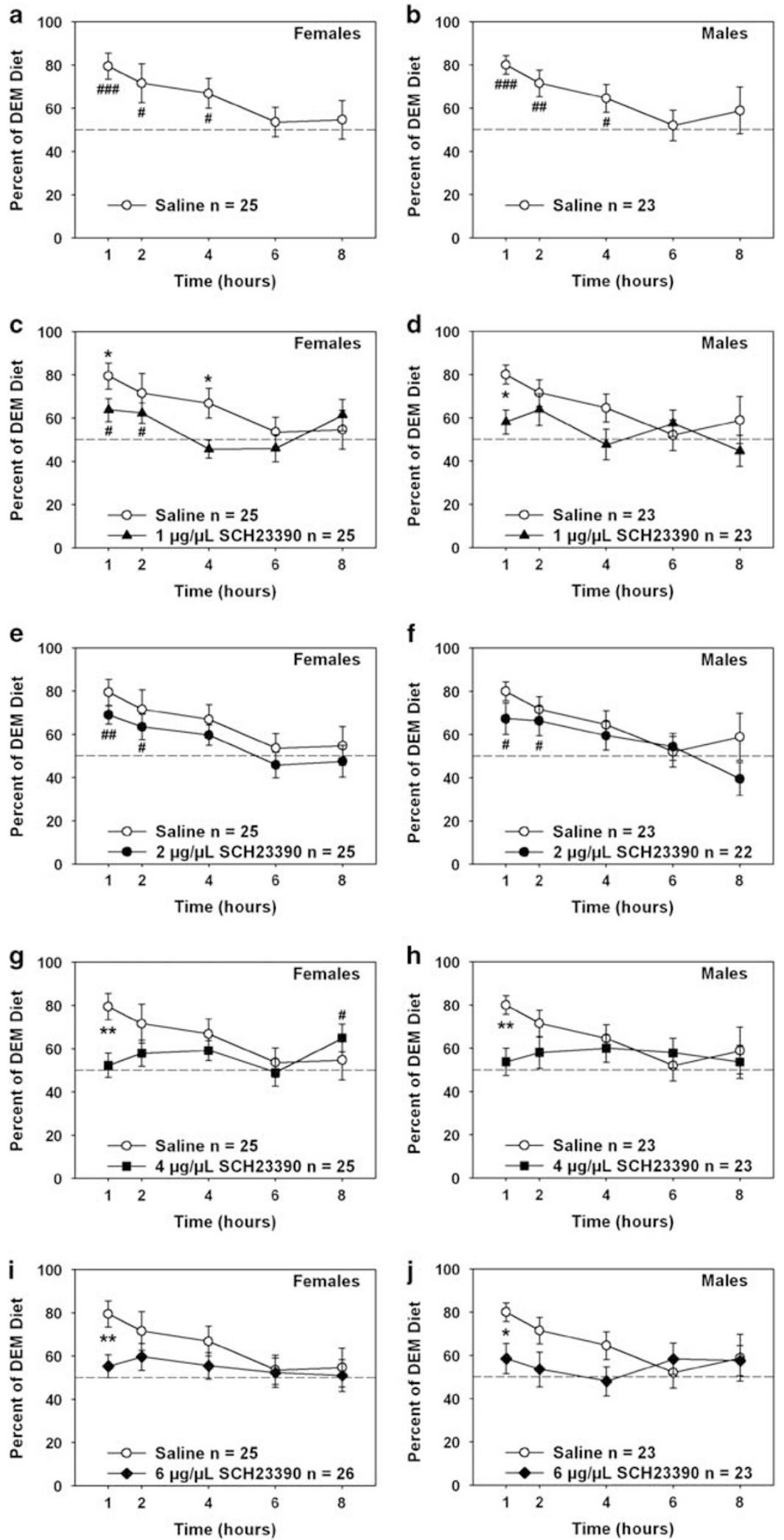

Figure 3 The percent of demonstrator (DEM) diet (DEM diet eaten divided by the total amount of food eaten) for female (a, c, e, $g, i)$ and male (b, $d, f, h, j)$ observer (OBS) mice that were administered a single dorsal hippocampal infusion of either saline vehicle (a, b; white circles) or the DI-type receptor antagonist SCH23390 at I $\mu \mathrm{g} / \mu \mathrm{ll}$ (c, d; black triangles), $2 \mu \mathrm{g} / \mu \mathrm{ll}$ (e, f; black circles), $4 \mu \mathrm{g} / \mu \mathrm{l}$ (g, h; black squares), or $6 \mu \mathrm{g} / \mu \mathrm{l}$ (i, j; black diamonds) I5 min before a 30 min social interaction (where social learning occurs) with a same-sex DEM conspecific that recently ate either a I\% cinnamon (CIN) or a $2 \%$ cocoa (COC) diet. DEM preference scores are shown at I, 2, 4, 6, and $8 \mathrm{~h}$ into the OBS choice test. Data are presented as mean \pm SEM. The $n$ reported in the figures reflect the number of OBS mice per group. ${ }^{*} p<0.05$, $* * 0<0.01$ in comparison between OBS mice that were infused with saline versus OBS mice that were infused with $\mathrm{SCH} 23390$ (for each sex). ${ }^{\#} p<0.05,{ }^{\# \#} p<0.01$, ${ }^{\# \#} p<0.001$ in comparison with $50 \%$ (chance). 

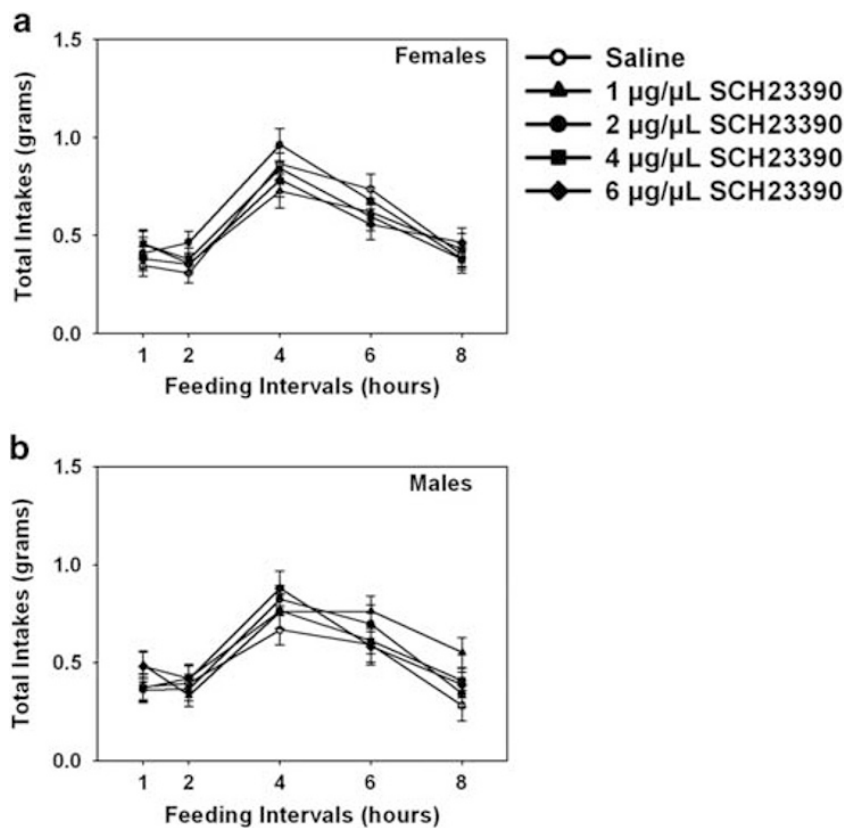

Figure 4 The total food intake (I\% cinnamon (CIN) diet+2\% cocoa (COC) diet) for female (a) and male (b) observer (OBS) mice that were administered a single dorsal hippocampal infusion of either saline vehicle (white circles; $n=25$ for females and $n=23$ for males) or the DI-type receptor antagonist $\mathrm{SCH} 23390$ at I $\mu \mathrm{g} / \mu \mathrm{l}$ (black triangles; $n=25$ for females and $n=23$ for males), $2 \mu g / \mu l$ (black circles; $n=25$ for females and $n=22$ for males), $4 \mu \mathrm{g} / \mathrm{\mu l}$ (black squares; $n=25$ for females and $n=23$ for males), or $6 \mathrm{\mu g} / \mathrm{\mu l}$ (black diamonds; $n=26$ for females and $n=23$ for males) $15 \mathrm{~min}$ before a 30 min social interaction (where social learning occurs) with a same-sex demonstrator (DEM) conspecific that recently ate either a CIN or COC diet. Total food intakes are shown at I, 2, 4, 6, and $8 \mathrm{~h}$ into the OBS choice test. SCH23390 treatment did not significantly affect either female (a) or male (b) total food intakes. Data are presented as mean \pm SEM.

$t$-tests also revealed that in the fourth hour of the choice test, females infused with $1 \mu \mathrm{g} / \mu \mathrm{l}$ of SCH 23390 had a significantly lower preference for their DEM diet $(t(41)=2.57, p=0.014)$ than saline-infused OBS female mice (as shown in Figure 3c). One-sample $t$-tests comparing the DEM preference scores with $50 \%$ (chance) further revealed that in the first and second hours of the choice test, OBS females ( $1 \mathrm{~h}$ : $t(16)=4.51, p<0.001 ; 2 \mathrm{~h}: t(16)=2.30, p=0.035)$ and males (1 h: $t(18)=6.00, \quad p<0.001 ; 2$ h: $t(19)=3.57, p=0.002)$ infused with saline, females infused with $1 \mu \mathrm{g} / \mu \mathrm{l}$ ( $1 \mathrm{~h}$ : $t(19)=2.47, p=0.023 ; 2 \mathrm{~h}: t(19)=2.53, p=0.02)$, and females (1 h: $t(15)=3.93, p=0.001 ; 2 \mathrm{~h}: t(21)=2.15, p=0.044)$ and males ( 1 h: $t(16)=2.58, p=0.02 ; 2 \mathrm{~h}: t(16)=2.46, p=0.026)$ infused with $2 \mu \mathrm{g} / \mu \mathrm{l}$ of SCH 23390 had significantly higher DEM preference scores than $50 \%$. In the fourth hour of the choice test, OBS females $(t(21)=2.37, p=0.027)$ and males $(t(20)=2.34, p=0.03)$ infused with saline still had DEM preference scores significantly higher than chance levels. Finally, OBS females infused with $4 \mu \mathrm{g} / \mu \mathrm{l}$ of SCH23390 had significantly higher DEM preference scores $(t(15)=2.42$, $p=0.029$ ) than $50 \%$ (chance) in the eighth hour. Notably, the DEM preference scores of males infused with 1 and $4 \mu \mathrm{g} / \mu \mathrm{l}$, and females and males infused with $6 \mu \mathrm{g} / \mu \mathrm{l}$ of SCH 23390 were not significantly different than $50 \%$ at any time points (as shown in Figure 3). Thus, the preference for the DEM diet displayed by SCH23390-infused female and male OBS mice was weaker than that of control saline-infused OBS mice, and not different than 50\% (chance), directly demonstrating an impairing effect of intrahippocampal SCH23390 on social learning.

The ANOVA conducted on the total food intakes of all OBSs revealed a significant main effect of time $(F(4,920)=$ 87.49, $p<0.001$ ), but no significant main effect of treatment or sex, and no interactions. Consistently, separate ANOVAs conducted on only females or males revealed no significant main effect of treatment and no interactions (as shown in Figure $4 \mathrm{a}$ and b). Hence, the social learning impairment due to intrahippocampal SCH23390 could not be directly explained by general changes in feeding behavior.

\section{Olfaction Control Study: Intrahippocampal SCH23390 Does Not Affect Male or Female Olfactory Discrimination}

See Supplementary Information for a detailed report of these results. Briefly, females and males (as shown in Supplementary Figure S13a and b) infused with SCH23390 at the highest dose $(6 \mu \mathrm{g} / \mu \mathrm{l})$ that also blocked social learning could discriminate between the two diets used in the choice test in the STFP. Thus, the social learning impairment was not due to $\mathrm{SCH} 23390$ impairing olfactory discrimination.

\section{DISCUSSION}

This study found that intrahippocampal SCH23390 blocks social learning in both males and females, and affects social behaviors in a sex-specific manner, without affecting food intake, oronasal investigation, or olfactory discrimination. These results are in agreement with our previous work using systemic treatments (Choleris et al, 2011), and find the dorsal hippocampus as a site of action underlying those effects.

A detailed behavioral analysis of the social interactions (see Supplementary Information for detailed discussion of the full results) revealed that the social learning impairment found in this study cannot be directly explained by a reduced exposure to the socially carried food odor found on the breath of the DEM, as the OBS oronasal investigation durations (as shown in Figure 1) were not affected by intrahippocampal SCH23390 in either sex. These results are in line with those of our previous study with systemic treatments that found the doses of SCH23390 that impaired social learning did not affect oronasal investigation (Choleris et al, 2011).

We cannot directly rule out the possibility that reduced generalized arousal (Calderon et al, 2016) may have contributed to the social learning impairment, possibly by reducing the interest expressed by the OBS toward the DEM conspecific. In addition, it is possible that the salience of the olfactory cues being emitted by the DEM may be reduced by reduced general arousal. To the best of our knowledge, no study to date has shown that reduced arousal can directly suppress social learning, or that arousal can directly mediate the later food preference of OBSs. The involvement of arousal in social learning remains a question for future investigations.

Our results identify the dorsal hippocampus as a structure that can mediate socially acquired food preferences through 
D1-type receptors, and extends to social learning previous intrahippocampal SCH23390 findings with nonsocial types of learning, and genetic studies using D1 KO mice investigating spatial learning, fear conditioning, and inhibitory and passive avoidance learning, all showing an involvement of dorsal hippocampal D1-type receptors (reviewed in Hansen and Manahan-Vaughan, 2014). Our findings therefore suggest similar underlying dopaminergic mechanisms for social and nonsocial learning.

Based on a model offered by Hansen and ManahanVaughan (2014), we propose that antagonizing hippocampal D1-type receptors with SCH23390 may have prevented the threshold for novel information (novel diet odor emitted by the DEM) entry into the dorsal hippocampus from being reached (Floresco et al, 2003; Lemon and ManahanVaughan, 2011). DA is released in the mouse hippocampus after encountering novel stimuli (Ihalainen et al, 1999), and dorsal hippocampal D1-type receptors are strongly involved in the processing of motivationally relevant novel information (Lisman and Grace, 2005; Otmakhova and Lisman, 1996; Rossato et al, 2009). Alternatively, the threshold may have been met, but the signal may have never left the hippocampus, and therefore did not arrive to intermediate structures such as nucleus accumbens (NAc)/ventral palladium - that have both been implicated in the integration of novel information signaling (Lisman and Grace, 2005). The above-mentioned intermediate structures were therefore unable to finally act on the VTA that is ultimately involved in establishing the formation of a hippocampal-dependent engram via increased hippocampal DA release (Hansen and Manahan-Vaughan, 2014; Lisman and Grace, 2005). Thus, dorsal hippocampal DA may foster the STFP by enhancing the novelty/salience of the olfactory stimulus (through D1-type receptors) and this in turn promotes learning of a new food preference.

Many studies have investigated D1-type receptors in mesocorticolimbic brain regions in individually acquired food preferences for highly palatable sweet foods. For example, antagonizing D1-type receptors in the medial prefrontal cortex (mPFC), amygdala, NAc, or hypothalamus blocks the acquisition, but not the expression, of a glucoseconditioned flavor preference (see Sclafani et al, 2011), as well as fructose-conditioned flavor preferences (Amador et al, 2014; Bernal et al, 2008; Malkusz et al, 2012). The current results further suggest the dorsal hippocampus can regulate dopaminergic effects on socially acquired food preferences similarly to other already identified brain regions. The STFP is a distinctly social form of learning that has been suggested to be analogous to associative conditioning (Heyes and Durlach, 1990). Whether or not these results on social learning extend to conditioned food preferences that are not acquired socially remains to be determined.

Consistent with our previous findings with systemic treatments (Choleris et al, 2011), this study found that intrahippocampal SCH23390 did not affect total food intake (as shown in Figure 4). These results are also in agreement with other studies reporting no effects of D1-type receptor antagonism in the orbitofrontal cortex (Cetin et al, 2004), lateral hypothalamus (Chen et al, 2014), dorsal mPFC (Nair et al, 2011), or NAc (Baldo et al, 2002) on food intake. Hence, dorsal hippocampal D1-type receptors regulate socially transmitted food preferences, but not feeding behavior in the STFP per se.

An ODT control study showed that in both female and male mice (as shown in Supplementary Figure S13a and b), intrahippocampal infusions of SCH23390 at the highest dose that blocked the STFP did not prevent the discrimination between the two diets used in the social learning test. Hence, the social learning impairment found in this study cannot be directly explained by any changes in olfactory discrimination, in agreement with our previous study showing no effects of SCH23390 on COC/CIN discrimination after systemic treatments (Choleris et al, 2011).

Female social learning was only blocked by the highest dose of SCH23390 $(6 \mu \mathrm{g} / \mu \mathrm{l})$, whereas male social learning was blocked by the lowest $(1 \mu \mathrm{g} / \mu \mathrm{l})$ and two highest doses (4 and $6 \mu \mathrm{g} / \mu \mathrm{l}$ ) of SCH23390 (as shown in Figure 2). Hence, although intrahippocampal SCH 23390 blocked social learning in both sexes, females were somewhat less affected by drug treatment than males. These results are in agreement with literature showing female gonadal steroids (estrogens/ progesterone) may have a neuroprotective effect on females (Brann et al, 2007; Wise et al, 2005) and promote learning (Phan et al, 2015). In addition, we found no interaction between the estrous cycle with intrahippocampal SCH23390 effects on either social learning or food intake. This was unexpected as the estrous cycle regulates the STFP and feeding in mice (Choleris et al, 2011). These findings are likely because of the small number of females at a given phase of the estrous cycle for each dose (Supplementary Table S5). Further research on the interaction between gonadal steroids and the dopaminergic system and their effects on social learning and feeding behavior is therefore warranted.

Collectively, this study found that dorsal hippocampal D1-type receptors mediate social learning and social interactions but not food intake in male and female mice. It may be useful for future studies on the neurobiology of social learning to investigate the role of D2-type receptors, and the possible involvement of other DA-dependent brain regions, such as the NAc, VTA, substantia nigra, or amygdala. Ultimately, this research may have implications for understanding abnormalities in the functioning of the social brain.

\section{FUNDING AND DISCLOSURE}

The authors declare no conflict of interest.

\section{ACKNOWLEDGMENTS}

We thank Michelle Kivlenieks, Opoku Adjei-Afriyie, and Angela Meersseman for their help with data collection. The research described here was funded by a research grant to Elena Choleris from the Natural Sciences and Engineering Council of Canada (NSERC). We thank the Ontario Student Assistance Program for graduate scholarships to Richard Matta who was also supported by an Ontario Graduate Scholarship and Queen Elizabeth II Graduate Scholarships in Science and Technology. 


\section{REFERENCES}

Amador NJ, Rotella FM, Bernal SY, Malkusz D, Cruz JA, Badalia A et al (2014). Effect of dopamine D1 and D2 receptor antagonism in the lateral hypothalamus on the expression and acquisition of fructose-conditioned flavor preference in rats. Brain Res 1542: 70-78.

Arakawa H, Kelliher KR, Zufall F, Munger SD (2013). The receptor guanylyl cyclase type D (GC-D) ligand uroguanylin promotes the acquisition of food preferences in mice. Chem Senses 38: 391-397.

Baldo BA, Sadeghian K, Basso AM, Kelley AE (2002). Effects of selective dopamine D1 or D2 receptor blockade within nucleus accumbens subregions on ingestive behavior and associated motor activity. Behav Brain Res 137: 165-177.

Bernal SY, Dostova I, Kest A, Abayev Y, Kandova E, Touzani K et al (2008). Role of dopamine D1 and D2 receptors in the nucleus accumbens shell on the acquisition and expression of fructoseconditioned flavor-flavor preferences in rats. Behav Brain Res 190: $59-66$.

Box HO (1984). Primate Behavior and Social Ecology. Chapman \& Hall: London.

Brann DW, Dhandapani K, Wakade C, Mahesh VB, Khan MM (2007). Neurotrophic and neuroprotective actions of estrogen: basic mechanisms and clinical implications. Steroids 72: 381-405.

Bunsey M, Eichenbaum H (1995). Selective damage to the hippocampal region blocks long-term retention of a natural and nonspatial stimulus-stimulus association. Hippocampus 5: 546-556.

Calderon DP, Kilinc M, Maritan A, Banavar JR, Pfaff D (2016). Generalized CNS arousal: an elementary force within the vertebrate nervous system. Neurosci Biobehav Rev 68: 167-176.

Cetin T, Freudenberg F, Füchtemeier M, Koch M (2004). Dopamine in the orbitofrontal cortex regulates operant responding under a progressive ratio of reinforcement in rats. Neurosci Lett 370: 114-117.

Chen YW, Morganstern I, Barson JR, Hoebel BG, Leibowitz SF (2014). Differential role of D1 and D2 receptors in the perifornical lateral hypothalamus in controlling ethanol drinking and food intake: possible interaction with local orexin neurons. Alcohol Clin Exp Res 38: 777-786.

Choleris E, Clipperton-Allen AE, Gray DG, Diaz-Gonzalez S, Welsman RG (2011). Differential effects of dopamine receptor D1-type and D2-type antagonists and phase of the estrous cycle on social learning of food preferences, feeding, and social interactions in mice. Neuropsychopharmacology 36: 1689-1702.

Choleris E, Clipperton-Allen AE, Phan A, Kavaliers M (2009). Neuroendocrinology of social information processing in rats and mice. Front Neuroendocrinol 30: 442-459.

Choleris E, Gustafsson JA, Korach KS, Muglia LJ, Pfaff DW, Ogawa S (2003). An estrogen-dependent four-gene micronet regulating social recognition: a study with oxytocin and estrogen receptor-alpha and -beta knockout mice. Proc Natl Acad Sci USA 100: 6192-6197.

Clark RE, Broadbent NJ, Zola SM, Squire LR (2002). Anterograde amnesia and temporally graded retrograde amnesia for a nonspatial memory task after lesions of hippocampus and subiculum. J Neurosci 22: 4663-4669.

Clipperton AE, Spinato JM, Chernets C, Pfaff DW, Choleris E (2008). Differential effects of estrogen receptor alpha and beta specific agonists on social learning of food preferences in female mice. Neuropsychopharmacology 33: 2362-2375.

Countryman R, Gold PE (2007). Rapid forgetting of social transmission of food preferences in aged rats: relationship to hippocampal CREB activation. Learn Mem 14: 350-358.

Ervin KSJ, Lymer JM, Matta R, Clipperton Allen AE, Kavaliers M, Choleris E (2015). Estrogen involvement in social behavior in rodents: rapid and long-term actions. Horm Behav 74: 53-76.
Floresco SB, West AR, Ash B, Moore H, Grace AA (2003). Afferent modulation of dopamine neuron firing differentially regulates tonic and phasic dopamine transmission. Nat Neurosci 6: 968-973.

Galef BG Jr (1988). Imitation in animals: history, definitions and interpretation of the data from the psychological laboratory. In: Zentall T, Galef BJ (eds). Social Learning: Psychological and Biological Perspectives. Erlbaum: Hillsdale, NJ. pp 3-28.

Galef BG Jr, Kennett DJ, Wigmore SW (1984). Transfer of information concerning distant foods in rats-a robust phenomenon. Anim Learn Behav 12: 292-296.

Galef BG Jr, Mason JR, Preti G, Bean NJ (1988). Carbon-disulfidea semiochemical mediating socially-induced diet choice in rats. Physiol Behav 42: 119-124.

Galef BG Jr, Stein M (1985). Demonstrator influence on observer diet preference: analyses of critical social interactions and olfactory signals. Anim Learn Behav 13: 31-38.

Hansen N, Manahan-Vaughan D (2014). Dopamine D1/D5 receptors mediate informational saliency that promotes persistent hippocampal long-term plasticity. Cereb Cortex 24: 845-858.

Heyes CM (1994). Social learning in animals: categories and mechanism. Biol Rev 69: 207-231.

Heyes CM, Durlach PJ (1990). Social blockade of taste-aversion learning in Norway rats (Rattus norvegicus): is it a social phenomenon? J Comp Psychol 104: 82-87.

Hoppitt WJE, Laland KN (2013). Social Learning: An Introduction to Mechanisms, Methods, and Models. Princeton: Princeton University Press.

Hyttel J (1983). SCH 23390 - the first selective dopamine D-1 antagonist. Eur J Pharmacol 91: 153-154.

Ihalainen JA, Riekkinen P Jr, Feenstra MG (1999). Comparison of dopamine and noradrenaline release in mouse prefrontal cortex, striatum and hippocampus using microdialysis. Neurosci Lett 277: 71-74.

Lemon N, Manahan-Vaughan D (2011). Dopamine D1/D5 receptors contribute to de novo hippocampal LTD mediated by novel spatial exploration or locus coeruleus activity. Cereb Cortex 22: $2131-2138$.

Lisman JE, Grace AA (2005). The hippocampal-VTA loop: controlling the entry of information into long-term memory. Neuron 46: 703-713.

Malkusz DC, Banakos T, Mohamed A, Vongwattanakit T, Malkusz G, Saeed S et al (2012). Dopamine signaling in the medial prefrontal cortex and amygdala is required for the acquisition of fructose-conditioned flavor preferences in rats. Behav Brain Res 233: 500-507.

Matta R, Ervin KSJ, Choleris E. The neurobiology of social learning. In: Olmstead MC (ed). Animal cognition: Principles, evolution, and development. NOVA Science Publishers: Hauppauge, NY, 2016, pp 171-200.

McNamara CG, Tejero-Cantero A, Trouche S, Campo-Urriza N, Dupret D (2014). Dopaminergic neurons promote hippocampal reactivation and spatial memory persistence. Nat Neurosci 17: $1658-1660$.

Munger SD, Leinders-Zufall T, McDougall LM, Cockerman RE, Schmid A, Wandernoth P et al (2010). An olfactory subsystem that detects carbon disulfide and mediates food-related social learning. Curr Biol 20: 1438-1444.

Nair SG, Navarre BM, Cifani C, Pickens CL, Bossert JM, Shaham Y (2011). Role of dorsal medial prefrontal cortex dopamine D1family receptors in relapse to high-fat food seeking induced by the anxiogenic drug yohimbine. Neuropsychopharmacology 36: 497-510.

Nakagawa S (2004). A farewell to Bonferroni: the problems of low statistical power and publication bias. Behav Ecol 15: 1044-1045.

Otmakhova NA, Lisman JE (1996). D1/D5 dopamine receptor activation increases the magnitude of early long-term potentiation at CA1 hippocampal synapses. J Neurosci 16: 7478-7486. 
Phan A, Suschkov S, Molinaro L, Reynolds K, Lymer JM, Bailey CDC et al (2015). Rapid increases in immature synapses parallel estrogen-induced hippocampal learning enhancements. Proc Natl Acad Sci USA 112: 16018-16023.

Rodriguiz RM, Chu R, Caron MG, Wetsel WC (2004). Aberrant responses in social interaction of dopamine transporter knockout mice. Behav Brain Res 148: 185-198.

Rosenthal R, Rosnow RL (1991). Essentials of Behavioral Research: Methods and Data Analysis2nd ednMcGraw Hill: New York.

Rossato JI, Bevilaqua LR, Izquierdo I, Medina JH, Cammarota M (2009). Dopamine controls persistence of long-term memory storage. Science 325: 1017-1020.

Russon AE (1997). Exploiting the expertise of others. In: Whiten A, Byrne RW (eds). Machiavellian Intelligence II: Extension and Evaluations. Cambridge University Press: New York. pp 174-231.

Sanchez-Andrade G, James BM, Kendrick KM (2005). Neural encoding of olfactory recognition memory. J Reprod Dev 51: $547-558$
Sclafani A, Touzani K, Bodnar RJ (2011). Dopamine and learned food preferences. Physiol Behav 104: 64-68.

Thompson TL, Moss RL (1997). Modulation of mesolimbic dopaminergic activity over the rat estrous cycle. Neurosci Lett 229: 145-148.

Valsecchi P, Galef BG Jr (1989). Social influences on the food preferences of house mice (Mus musculus). Int $J$ Comparat Psychol 2: 245-256.

Wise RA (2004). Rewards wanted: molecular mechanisms of motivation. Discov Med 22: 180-186.

Wise PM, Dubal DB, Rau SW, Brown CM, Suzuki S (2005). Are estrogens protective or risk factors in brain injury and neurodegeneration? Reevaluation after the Women's health initiative. Endocr Rev 26: 308-312.

Wong P, Chang CCR, Marx CE, Caron MG, Wetsel WC, Zhang X (2012). Pregnenolone rescues schizophrenia-like behavior in dopamine transporter knockout mice. PLoS ONE 7: e51455.

Supplementary Information accompanies the paper on the Neuropsychopharmacology website (http://www.nature.com/npp) 